\title{
The Determinants of the Economic-Sexual Exchange Faced with the Risks of Aids to Humans (The Mountainous West of the Ivory Coast)
}

Tchehi Zananhi Florian-Joël*

Teacher-Researcher; Socio-Economist of Development) at the Jean Lorougnon Guédé University (Ivory Coast)

DOI: $10.36347 /$ sjahss.2020.v08i06.005

| Received: 10.06.2020 | Accepted: 18.06.2020 | Published: 28.06.2020

*Corresponding author: Tchehi Zananhi Florian-Joël

Abstract

Original Research Article

The monetization of social relations, through economic-sexual exchange poses a problem of health risks in the face of the spread of AIDS. These economic-sexual practices which seem to challenge the AIDS pandemic motivated this study, to understand the determinants. Part of a qualitative approach, this study mobilizes techniques such as documentary research, direct observation and individual interviews. The related tools are, among others, the reading grid, the observation grid and the interview guides. These made it possible to realize that the factors which determine economic-sexual exchange in the face of the risks of AIDS, relate to poverty, parental influence, environmental influence and imitation.

Keywords: economic-sexual exchange, sex worker, AIDS, social relationship.

Copyright @ 2020: This is an open-access article distributed under the terms of the Creative Commons Attribution license which permits unrestricted use, distribution, and reproduction in any medium for non-commercial use (NonCommercial, or CC-BY-NC) provided the original author and source are credited.

\section{INTRODUCTION}

The structuring of social relations from the angle of games of interest depicts for this purpose a system of social materialism in the sense of Karl Marx [1]. Indeed, this economic vision of social relationships was accentuated in sexuality, to give birth to economicsexual exchange [2]. Talking about economic-sexual exchange is an analyzer of the compensation system for having sex in an economic form. Sexual intercourse thus becomes a service rendered by one partner to the other in exchange for said compensation, without sometimes measuring the risks run by one or the other of the swingers. Seen from this angle, female sexuality becomes a product that can be sold or bought.

Meanwhile, the lexicography on the economicsexual exchange in Africa, relates the exposure of sex workers to AIDS in this socioeconomic action game.

If the study of sexual transactions, which emerged in particular in the context of the HIV epidemic and Africanist feminist studies, is particularly interested in the realization and multiplication of sexual relations, the forces contributing to it, it is permissible to define more precisely the economic-sexual exchange as being at the hinge of social sex relations. Given the "banality" of the economic-sexual exchange, it is important to understand it as a product of male domination. How then can we analyze the existence of sexual transactions in relationships that are structured around social relationships other than those of sex?

The economic dimension plays a major role in men's access to women's sexuality and those who have fewer resources are not only marginalized from the dominant masculinity but see it as a "reversal of power relations to their disadvantage [3]. In this affirmation of masculinity through the monetarization of social relationships, the health risks faced with sexuality are minimized. In this dynamic, economic-sexual exchanges are negotiated and renegotiated in the social relations of sex but also within other relations, in particular relations of economic power with the "monetarization of sexuality and feelings in Africa. (Idem, p. 154)

In fact, in Africa, and particularly in Côte d'Ivoire, HIV infection is mainly transmitted sexually. Sex traders and their partners are highly vulnerable people by profession [7]. Côte d'Ivoire is one of the countries most affected by HIV / AIDS in West Africa, where the prevalence rate is estimated at $3.7 \%$ (Idem, p. 16). This rate has given rise to awareness-raising and priority actions by the Ivorian government in order to reduce this scourge. This rate hides disparities in specific populations known as highly vulnerable populations (PHV) among which the sex traders of all sexes account for $27 \%$ and the female traders, in particular, are estimated at $11.4 \%$. 
How can we understand that the prevalence rate is not declining, despite awareness-raising and efforts to combat this scourge?

What are the determinants underlying the economicsexual exchange faced with the risk of AIDS?

The answer to these questions is necessary to understand the dynamics of economic-sexual exchange in Man.

\section{RESEARCH METHODOLOGY Methodology}

Our re fl ection on "The determinants of sexeconomic exchange faced with the risks of AIDS in Man in the mountainous west of the Ivory Coast. ", Follows a methodology which is rooted in a certain number of theoretical considerations which it is important to elucidate before progressing in our analysis.

\section{DATA COLLECTION \\ Data collection techniques}

The techniques or instruments for collecting data must be understood as: "defined, transmissible operating procedures, successive to be applied under the same conditions adapted to the type of problem and phenomenon involved" [5].

In this context, the techniques call on several mechanisms to achieve the expected results. As this research work is part of a qualitative approach, the techniques we have used are: documentary research, direct observation and individual interviews.

\section{Data Collection Tools}

The qualitative research techniques used in this study mobilized the following tools: a reading grid, an observation grid and interview guides.

\section{Sampling technique}

For this article, we opted for network sampling which a non-probability is sampling technique consisting in choosing in our sociological field the Sex Professionals of the city of Man. The choice fell on the waitresses of the maquis and bars, the hairdressers, the students, the unemployed (girls and boys) aged 18 and over who are sex workers and who seem best suited to illustrate the apprehension on the subject. On this basis, sex workers (PS) were chosen according to their availability or accessibility in a specific environment and at a specific time and on the proposal of the first respondents or even through social networks, friendships. We continued the process to the desired size 60 people. The choice of this sampling technique is justified by the unavailability of most and the difficult interference of the environment.

Thus, the inclusion and exclusion criterion consisted in choosing any PS available and willing to answer our questions. The application of this method allowed us to collect qualitative data from these same actors.

\section{Use of the data collected \\ Data processing}

The data collected underwent computer processing with Sphinx 5.1 software. The information thus processed made it possible to draw up this article.

\section{The theoretical foundations of data analysis}

Theoretical theorists, including Edmund Husserl, maintain that the phenomena do not appear to the actors; they are lived by them. Therefore, it is the lived experience that must be captured. Phenomenology thus privileges the point of view of the actors. She attaches importance to the interpretation that the actors give of the events they experience. This approach promotes "synthetic" or "reconstructive" intuition, and lived experience where the hypothetico-deductive approach proceeds to reasoning based on the observation of constancy. The phenomenological approach has made it possible to identify and analyze the social and environmental factors at the origin of risky sexual behavior by sex workers.

Analysis of data in the field is organized around two main theories: imitation [6] and social learning [7]. Late in the theory of imitation offers two concepts to explain social words: one of them is imitation. Each imitates what he admires, what he deems good and capable of serving as a model, but arranges, in an original way, by their mixture, the imitations chosen from several sources. Indeed, what fundamentally motivates individuals is belief and desire. All beliefs are motivating, ideological beliefs but also others and it is desire that fuels belief.

From our perspective, the imitation is explained by the fact that Sex Professionals tend to rub shoulders with peers who also have sexual practices. In the family unit, at school, in the church or in the mosque, adolescents or adults frequent people who are sometimes older, for some and more experienced, for others. These people will become a model for them, and they will begin to idealize them and want to imitate them.

Social elders sometimes having certain sexual habits will develop a curiosity in the adolescent who will start to observe them and from there will be born certain desires. During historical development, human inventions bring the weapons which belief and desire need; it is the inventive genius of the individual which is the engine of social evolution. But society only appears thanks to the imitation which for Tarde is the primary and decisive factor in the appearance of the social bond between individuals. It is because they live together that men think and act the same way. Cohabitation will develop in the family unit and or at school the same ways of acting, of thinking. This 
cohabitation will allow discoveries among Sex Professionals because by dint of imitating those around him, he will develop links with social seniors, which will allow real integration.

Imitation explains the existence and repetition of the facts. It is not only the result of individuals, social groups are also imitated. Tarde offers imitation to explain the facts, the social movements. Each imitates what he admires, what he deems good and capable of serving as a model, but organizes in an original way, by mixing the chosen imitations from several sources. As a result, teenagers will imitate those they admire either out of sympathy or for his mania, for whatever reasons. This imitation will start by doing the same as the person he admires. But, it evolves because the sex workers, in their imitation will try to stand out from their mentors and find their own style.

Imitation becomes the foundation of the social bond. She discovers all aspects of social life. We first have innovations, discoveries that will spread by imitation of discoveries and by repetition by expanding. Cohabitation will allow the discovery of the sexual habits of the socio-family environment. After the discovery, the PS will seek to imitate their pairs or their elders. The imitation that will develop in them will create the repetition of the act (sexual attitudes, sexual practices,). They will repeat this act often because it is a discovery and they want to make the most of it. This repetition will promote the installation of the addiction.
According to Bandura [7], certain human behaviors are based on vicarious learning that is to say that comes from observing the behavior of other models. In social learning, behavior is an interactive determinant that influences the environment as well as the individual. It is the process of social building of the individual through social learning. Social constructivism is a current of contemporary sociology developed by Berger and Luckmann [8]. This approach envisages social reality and social phenomena as being "constructed", that is to say created and institutionalized and subsequently transformed into tradition. It focuses on the description of institutions, actions by questioning how they construct reality. "Socially constructed reality" is seen as a dynamic process; reality is reproduced by people who act according to their interpretation and their knowledge of it.

In the present study, this theory allows us to say that the actors build their sexual attitudes in their socio-family environment. The social system in which they live will allow them to stop or stay in these sexual behaviors. Thus, the actor will seek to build himself through the eyes of others. An individually constructed experience, the individual floats between what is pleasant for him and what is good in the eyes of society. He tends to modify his behavior when he feels observed.

\section{Location of the study field}

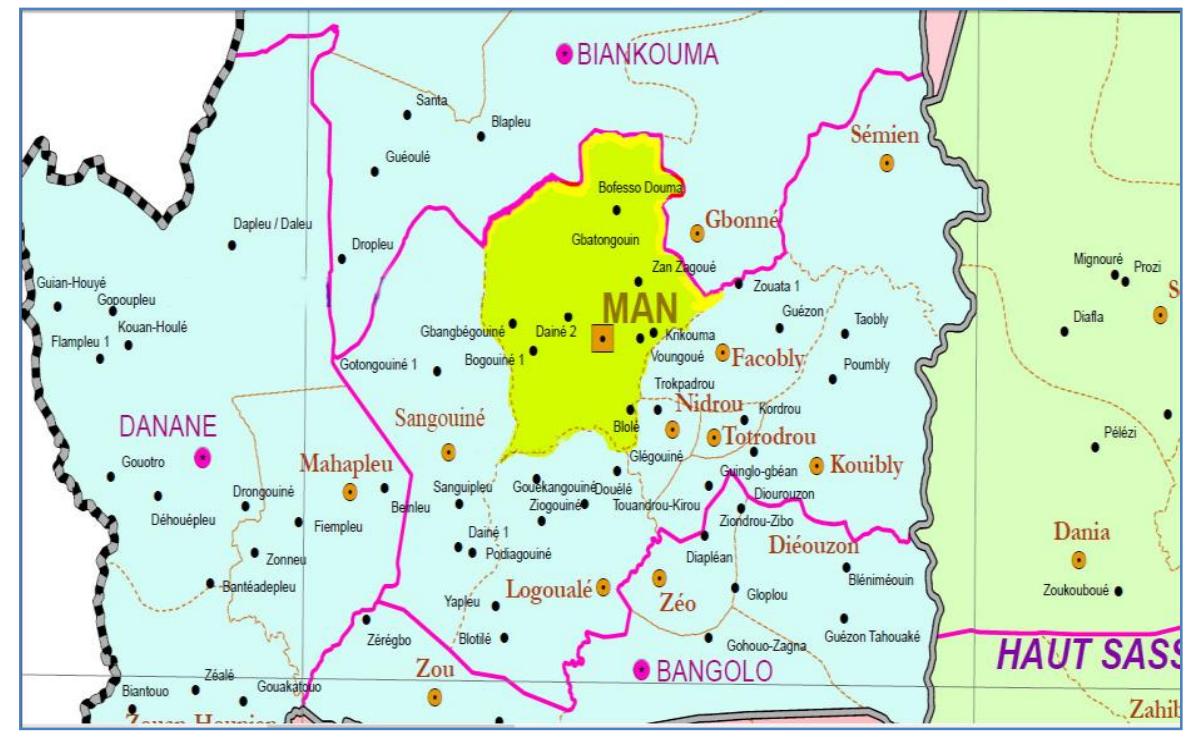

Source: Our study, 2019

\section{RESULTS AND DISCUSSION \\ Determinants of attitudes of Sex Professionals towards HIV / AIDS}

The sexual attitude is based on a set of elements that lead the Sex Professional (PS) to get involved in this activity. He ends up truly engaging in sexual vagrancy for a fee. Sex involves compensation1. "The existence of a continuum in the forms of sexual relations between man and woman implying an economic-sexual exchange" [9].

Our objective, here, is to give the essential reasons for the foundation of the economic-sexual exchange of Sex Professionals and the consequences that these could entail in the face of the risks of AIDS. 
Experience of the first sexual experience among Sex Professionals

Family influence

"I live with my aunt who practiced the trade. But I did not know at all. Each time she came with men who spent the night at home. When she came home that I am still standing (when I am not sleeping yet), I spend the night in the living room and they sleep in the bedroom. The days when I sleep before she comes home and she couldn't wake me up, the three of us, that is me, my aunt and her train station, we sleep in the same room [...] When they do love, moans wake me up. It was like that every time. It was a day, she told me to accompany her to a party where a gentleman invited her. We only went to "heat" (have fun) in an airconditioned bar me, my aunt and the gentleman (his client). That day we all slept in the same room and under the influence of alcohol he kissed me and everything was gone, we made love to three. The morning before we left, he gave us two envelopes where there was money. I had just turned 20. After that, he called me and we saw each other at the hotel when he needed me. " Solange, 22, Sex Professional.

According to the Interactionist theory of learning of L. Vygopski [10], thought and consciousness are determined by the activities carried out with fellow humans in a determined social environment. He considers that each superior function appears twice during the child's development. First, in a collective activity supported by adults and the social group; in the second time, during an individual activity, and it then becomes an internalized property of the child.

The family influence in Solange's first sexual experience comes from her aunt who was already a Sex Professional. The risks for her having sex too had increased, given that she had internalized the behavior of her aunt who had sex in their bedroom. This is explained by Bandura [7], arguing that certain human behaviors are based on social learning by observing the behavior of other models. This is what encouraged Solange's initiation into sex and this activity.

\section{Imitation, foundation of sexual attitude}

"A friend invited me to his birthday party at a nightclub [...] To tell the truth, I was surprised that we were only between us boys that day with gentlemen to whom my friend introduced me as his godfathers. During the party, I read the joy of living on the face of my friend and his comrades who smoked, drank and flirted at the same time between them boys and the show was total [...] I had nothing to lose by trying to do like them. One of the sponsors offered to flirt with me. I behaved well with him the whole night we spent together. So far, I'm doing very well in this business. " Léonce, 23 years old, student and Professional sex worker (Homosexual).
The fundamental principles of social dynamics and socialization are based on the imitation and invention of either. This is what is said [6] "Everything is socially only inventions and imitations". The integration of a social group obeys the principles of socializing its habits, their internalization and selfassertion by the reinvention of its personality.

" Let yourself go ! Kiss him, it doesn't matter, try and you will see, today we can do everything, you see it's your best friend's birthday so don't spoil the party [...] I really envied them, I couldn't no longer bear their pressure. But I never tried that between boys. This is how I got out of the nightclub and I negotiated with a PS and I went out with it (we made love). It was another time that the sponsor contacted me to invite me to a party. Again after several pressures I gave in, I wanted to try and now I'm more into it, it's my job. " Moustapha, 24, Sex worker (Homosexual).

The violence and influence of the group favored Moustapha's initiation into this activity. Building by the gaze of others, he wanted to imitate what he thought good or useful so as not to be worried by the other members of his group. Indeed, this first experience was just a desire to be like his friends.

\section{Sociocultural factors of sexual attitudes among Sex Professionals}

This dimension constitutes an important factor in the economic-sexual exchange and the social management of the risks linked to the AIDS of the Sex Professionals and more upstream the affective and sexual health. Indeed, the community to which sex workers belong is an essential starting point in a preventive approach to HIV / AIDS. It determines important characteristics (social, cultural, moral, and educational) of Sex Professionals. These factors reflect the fact that sexuality is not an isolable phenomenon, but is part of the cultural norms and valuesof each social group. They are associated with norms and values in matters of sexuality, nuptiality, family and fertility. The proposed review shows, where necessary, how they affect young people's sexuality. Rwenge [11].

\section{Influence of knowledge of HIV / AIDS}

This level concerns the methods of discussion of Sex Professionals around AIDS and their way of talking about it. It also allows us to observe the construction of their knowledge.

"There are people from the NGO IDE Africa who have campaigned on AIDS. They gave us condoms (condoms) with cards (leaflets). But, I did not go to school so everything they put in the file there, I did not understand. It was my colleague who taught me that it was about how to get AIDS and how to live with the disease. Otherwise, if it was me alone, I didn't understand anything. " Nady, 30 years old, Sex worker not in school. 
"[...] Like I did the benches (I went to school), often in our talks, my friends and I (between PS), we talk about it. I try a little to explain to them the modes of transmission of HIV / AIDS and how to avoid it (the disease) ". Natou, 29 years old, educated sex workers.

The majority of information is not given at the right time or seems to have left no knowledge acquired. There is a lack of access to information at the PS level.

Even when they are made aware of the risks linked to AIDS, their attitude is hardly changed in their swing from swingers.

\section{Influence of representations of HIV / AIDS}

"We don't even talk about that at home since it was my aunt herself who made me get into it. So she will tell me what? If we talk about it, it's as if she discourages me, as if she told me not to do that anymore. Mariette, 24, Sex Professional.

"With us, we don't talk about this subject, no, not even that I remember. It may happen that my mother has talks with my sisters on how to manage menstruation and how to make babies [...] In all cases my clients use condoms so I am far from getting AIDS ". Bélinda, 23, Sex Professional.

Bélinda and Mariette explain that it is impossible to talk about AIDS with their respective families. There is a lack of family dialogue. This can lead to disinterestedness in looking for the right information on HIV / AIDS. The taboo seems to be closely linked as much to "unauthorized" sexual intercourse as to virginity, which is inseparable from personal and family honor.

\section{Influence on the mode of sexual behavior}

"I am informed about AIDS, it really exists. I know that when you have AIDS automatically you are rejected by your family, your friends even abandon you and you no longer have support, they are all ashamed of you. This is why I force my clients to wear the condom. I always have this on me and I sell it to my customers. And before going out with you (having sex) I always check that you have worn the condom. I never went out with a client without a condom. Dominique, 26, Sex Professionals.
The individual infected with AIDS is not a neutral entity. He has pathological signs and symptoms that provoke reactions in others. These reactions go through the conventions and standards established and applied by members of a community. It is in this context that Dominique speaks of the rejection of HIV positive or AIDS patients. This rejection tendency is materialized by the condemnation and stigmatization of HIV-positive people, as well as their exclusion by their environment. AIDS would be a shameful disease that we don't talk about with our loved ones. Indeed, the image of AIDS is very negative, it is perceived as a cultural connotation focused on the violation of a prohibition on sexuality. In this dynamic the cultural influence on sexuality takes on its full meaning. Teresa de Lauretis [12] explains this system: "The cultural conceptions of the masculine and the feminine as complementary but mutually exclusive categories in relation to which all human beings are situated constitute a gender system, a symbolic system or a system of meanings, which correlate sex with cultural content according to hierarchical social values in all cultures.

\section{Consequences of the attitudes of sex workers towards HIV / AIDS}

Sexual intercourse by Sex Professionals in the past six months

Analysis of the graph below shows that 51 Sex Professionals surveyed, i.e. $92.7 \%$ had sexual intercourse in the last six months against 01 surveyed, or $1.8 \%$ who did not have sexual intercourse due to illness, including typhoid fever and malaria. 02 PS, or $3.6 \%$ who participated in the survey, did not answer the question. This graph highlights the sexuality of Sex Professionals. This shows the risk run by them. Indeed, they practice multi-sexual partnership. Almost all the SPs surveyed have more than two (02) sexual partners per day. First, those who have about 10 sexual partners per day are recorded, 25 respondents (49\%). Then come the respondents who have seven (07) sexual partners, 16 respondents $(31.4 \%)$. Then follow the PS who have six (06) sexual partners, 07 respondents $(13.7 \%)$. In last position, we have the respondents who have more than four (04) sexual partners, 03 respondents, or 5.9\%.

Rod diagram $n^{\circ} 1$ : Distribution of Sex Professionals by number of sexual partners

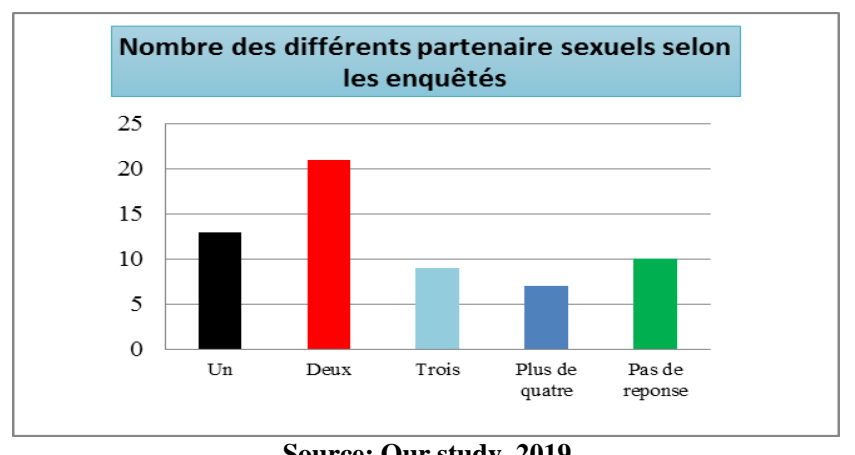

Source: Our study, 2019 
It can be seen from this graph that out of the 60 sex workers who participated in the survey only 01 $(1.8 \%)$ is not sexually active due to medical rest. This situation poses acutely the problem of the vulnerability of health workers to HIV / AIDS. They are at risk insofar as they have several sexual partners; which is an important factor in the chain of HIV / AIDS transmission. Added to this is the fact that the wearing of condoms is not always systematic for the following reasons according to the respondents: (i) the partner does not feel anything; (ii) the same customers have been around for a long time; (iii) trust; (iv) reduced pleasure and (v) condom allergies.

\section{The predominance of youth}

The majority 41 , or $74.5 \%$ of the population studied, is made up of young people.

Bar diagram $n{ }^{\circ} 2$ : Distribution of respondents by age group

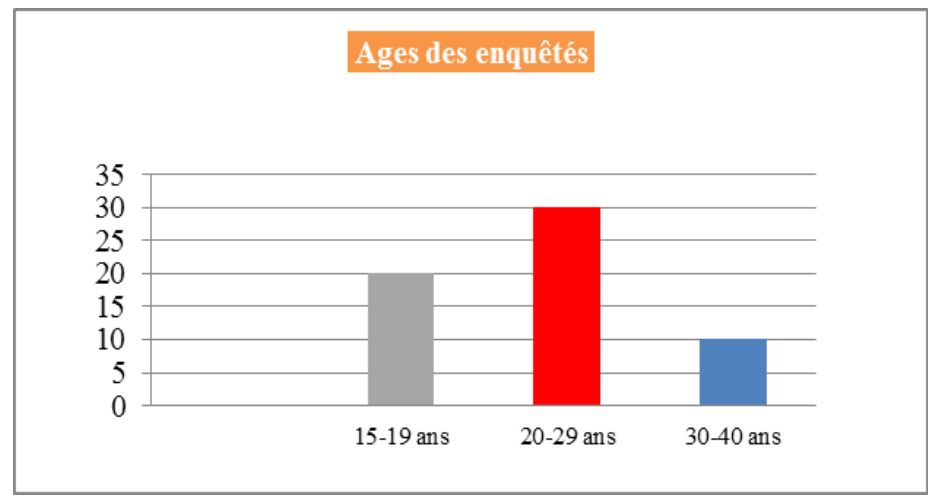

Source: Our study, 2019

The predominance of young people could be explained by the fact that they were the most numerous. Indeed, they were most willing to answer our questionnaires and there was enthusiasm at their levels. Furthermore, this age group is important in terms of the risk involved. At this stage, there is a conflict between adolescence and adulthood. The youngster believes that he is tall, so thinks of affording everything including the multiplication of sexual intercourse and therefore the risk of infection with HIV / AIDS.

\section{Sex for money}

The context of poverty, accentuated by the armed conflict, especially in the mountainous west of the Ivory Coast, constitutes a situation generating very significant risks. As a result, many SPs may be tempted to have sex in order to meet their material and financial needs. "The essential resource of the woman (her wealth or her" land ") is her sex" (Tabet, p. 26) The following remarks demonstrate this well: "[...] When my family and I were in Abidjan, my parents took good care of me. I had pocket money and I spent my vacations every year outside either in Nigeria or in South Africa [...] But with the crisis there, the armed conflict there, dad lost his job (his job) and suddenly we all found ourselves here in Man, at home, my hometown. There's no more money to pay for my schooling. Pocket money all that has been removed, it's myself I have to look for myself (take care of myself). Here's how I end up there. " Paco, 29, Responsible for Sex Professionals (Homosexual). "I know what is called sexual abstinence because I have practiced it until the age of 20. It was when I was 20 years old that I started this job because my parents no longer had the money to pay for school for my two brothers and me. A year ago
I was in it. Currently, what I'm doing here is my job, that's what gives me food, that's what feeds my little brothers (it's our source of income) [...] Know what job I do to pay for my two brothers' schooling ". Nice, 21 years old, Sex Professional.

According to this model, men are actively looking for women who are trading goods in this market. We recognize here the system of economicsexual exchange explained by Paola Tabet [9].

From this premise of a different relationship to sexuality according to gender follows a theory of the exchange of capital between men and women: economic or social capital, or both, of man against erotic capital of woman [13].

\section{Sex with arousal}

Sex workers can use stimulants for aphrodisiac purposes. Achieving "exceptional" sexual performance is the main motivation for this behavior. $10.5 \%$ of the PS surveyed admits having had sexual intercourse under the influence of an arousal. Homosexual health workers are the ones who use this practice the most. The use of stimulants is considered to be a stimulant before intercourse. Also, PS who is having their first sexual experience uses it sometimes. The stories of El Kaba and Princess Tiama justify it:

"I had never done this between men. It was my first time and I was scared and stressed. When the Guru with whom I was to go out (a client of a high socioeconomic category) knew that, we went to the bar and drank a very strong liqueur. He also asked me to smoke his cigar and told me that my stress would go away $[\ldots]$ 
which is why I didn't feel the pain the first time I did this. "El Kaba, 27, Sex worker, Homosexual.

"The very first time I had to do this was with a couple that a big brother from the neighborhood connected me to. There were three of us in bed, the lady, her husband and me. Before starting her husband brought cigarettes and wisky. And like me I don't smoke, I rather drank whiskey. They smoked and drank. I admit that it allowed me to be effective, they too were satisfied in the end. "Princess Tiama, 29, Sex Professional.

\section{CONCLUSION}

At the end of this study, it is important to note that the factors that determine economic-sexual exchange in the face of the risks of AIDS, relate to poverty, parental influence, environmental influence and imitation.

Also, this study revealed that Sex Professionals have their knowledge strongly influenced by false beliefs and are relatively prejudiced about HIV positive people. This therefore has a relatively large influence on sexual behavior. Also, the family unit plays a decisive role in the sexual behavior of health workers.

Sex workers can be considered vulnerable due to the lack of adequate information and the influences they experience. We can estimate then that the Sex Professionals of the locality of Man have sexual attitudes at risk of infection with HIV / AIDS, by the ignorance of the pandemic, the representations nourished by false beliefs, by the attitudes of rejection towards -vis HIV positive people.

\section{REFERENCES}

1. Lefebvre Henri. Le matérialisme dialectique. Paris: Presses Universitaires de France. Première édition: première édition Quadrige: 1990.
2. Tabet Paola. La Construction sociale de l'inégalité des sexes. Des outils et des corps. Paris-Montréal, L'Harmattan. 1998: 206

3. Omokaro O, Payton J. FlySensing: A case for crowdsensing in the air. In2014 IEEE International Conference on Pervasive Computing and Communication Workshops (PERCOM WORKSHOPS) 2014 Mar 24 (pp. 545-550). IEEE.

4. Plan Stratégique National 2016-2020 de lutte contre le sida et les infections sexuellement transmissibles.

5. N'da P. Recherche et méthodologie en sciences sociales et humaines: réussir sa thèse, son mémoire de master ou professionnel, et son article. Editions L'Harmattan; 2015 Mar 1.

6. Tarde G. Les lois de l'imitation, Félix Alcan, Paris ; Editions Kimé, Paris.1993

7. Bandura A. L'apprentissage social (J.-A. Rondal, trad.). Bruxelles: Pierre Mardaga.(Ouvrage original publié en 1977 sous le titre Social learning theory. Toronto: Prentice-Hall of Canada). 1980.

8. Berger PL, Luckmann T, Taminiaux P, Maffesoli M. La construction sociale de la réalité. A. Colin; 1996.

9. Tabet Paola. La grande arnaque. Sexualité des femmes et échange économico-sexuel, Paris, L'Harmattan; 2004.

10. Vygotski LS. Pensée et langage, Paris, La Dispute; Edition originale en langue russe; 1997.

11. Rwenge M. Facteurs contextuels de la transmission sexuelle du sida en Afrique subsaharienne: une synthèse. Vivre et penser le sida en Afrique, Codesria-Karthala: IRD, 1999b. 1999:216-36.

12. De Lauretis T. Théorie queer et cultures populaires. De Foucault à Cronenberg. Lectures, Les livres. 2007.

13. Hakim C. Erotic capital. European sociological review. 2010 Oct 1;26(5):499-518.

14. Hakim, Catherine. The Male Sexual Deficit: A Social Fact of the 21st Century, International Sociology.2015, 30, 3: 314-335. 